\title{
ERRATUM
}

\section{Erratum to: Evaluation of the Short-Term Cost-Effectiveness of IDegLira Versus Continued Up-Titration of Insulin Glargine U100 in Patients with Type 2 Diabetes in the USA}

Barnaby Hunt (D) - Michelle Mocarski · William J. Valentine •

Jakob Langer

Published online: May 18, 2017

(c) The Author(s) 2017. This article is an open access publication

Erratum to: Adv Ther (2017) 34:954-965

DOI $10.1007 / \mathrm{s} 12325-017-0502-2$

In the original publication, Figure 3 was published incorrectly with errors. In Fig. 3, the "Not defined" labels should appear in the "Insulin Glargine U100' row of the table beneath the figure. In place of these the values '41,530' and '57,642', respectively, should appear in the IDegLira row of the table beneath the figure. It has been corrected and the correct version is provided below.

The online version of the original article can be found under doi:10.1007/s12325-017-0502-2.

B. Hunt $(\varangle)$. W. J. Valentine

Ossian Health Economics and Communications,

Basel, Switzerland

e-mail: hunt@ossianconsulting.com

M. Mocarski

Novo Nordisk Inc., Plainsboro, NJ, USA

J. Langer

Novo Nordisk A/S, Søborg, Denmark 


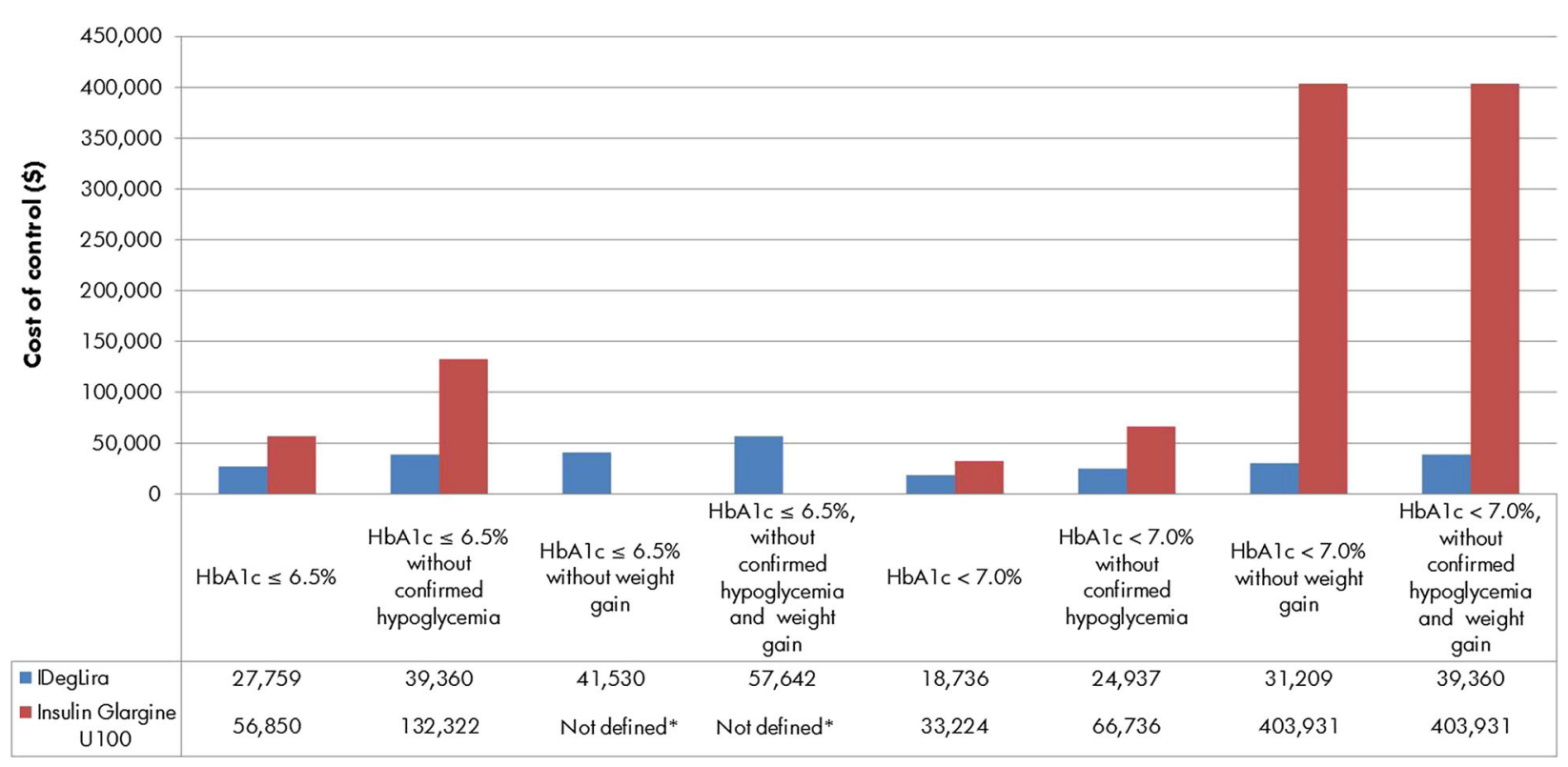

Fig. 3 Cost of control: patients with $\mathrm{HbAlc}>9.0 \%$ at baseline. \$, 2015 US dollars; HbA1c, glycated hemoglobin. ${ }^{*}$ Cost of control values cannot be calculated in the insulin glargine $\mathrm{U} 100$ arm for $\mathrm{HbA1c} \leq 6.5 \%$ without weight gain

Open Access. This article is distributed under the terms of the Creative Commons Attribution-NonCommercial 4.0 International License (http://creativecommons.org/licenses/ by-nc/4.0/), which permits any noncommercial use, distribution, and reproduction in any and HbAlc $\leq 6.5 \%$ without confirmed hypoglycemia and weight gain, as no patients in the insulin glargine U100 arm achieved these treatment targets

medium, provided you give appropriate credit to the original author(s) and the source, provide a link to the Creative Commons license, and indicate if changes were made. 